\title{
鄱阳湖流域含珍稀针叶树种的群落特征
}

\author{
方全 刘以珍 葛 刚 ${ }^{*}$
}

南昌大学生命科学学院鄱阳湖环境与资源利用教育部重点实验室, 南昌 330022

\begin{abstract}
摘 要 亚热带分布有众多珍稀针叶树种, 珍稀针叶植物的保护与濒危机制研究受到广泛关注。为了解鄱阳湖流域天然森林 植被中珍稀针叶树种的分布及其生存状况, 对其所在的植物群落进行调查。调查采用样方法, 样方面积 $20 \mathrm{~m} \times 20 \mathrm{~m}$, 记录样 方信息、群落物种组成及数量特征, 计算物种重要值, 分析了群落的类型及结构特征。样方分布于鄱阳湖流域内南岭山地、 罗宵山脉、武夷山脉、黄山山脉、九岭山脉。论文提供了 23 组详细的群落样方数据, 11 种珍稀针叶树种分布于 14 个不同群系 中, 珍稀针叶植物多以共建种或伴生种出现在群落中, 以针叶树为优势种的群系有南方红豆杉(Taxus wallichiana var. mairei) 林、黄杉(Pseudotsuga sinensis)林、福建柏(Fokienia hodginsii)林、榧树(Torreya grandis)林。
\end{abstract}

关键词 鄱阳湖流域; 珍稀针叶植物; 群落结构; 样方数据

引用格式: 方全, 刘以珍, 葛刚 (2016). 鄱阳湖流域含珍稀针叶树种的群落特征. 植物生态学报, 40, 952-957. doi: 10.17521/cjpe.2015.0454

\section{Characteristics of plant communities containing rare conifers in Poyang Lake Basin, China}

FANG Quan, LIU Yi-Zhen, and GE Gang*

School of Life Science, Key Laboratory of Poyang Lake Environment and Resource Utilization, Ministry of Education, Nanchang University, Nanchang 330022, China

\begin{abstract}
The endangerment mechanism of rare conifer species is a very critical problem in conservation biodiversity. Thus, the studies on the protection of the rare and endangered coniferous trees have received extensive attention. The objective of this study was to understand the survival and distribution of the rare coniferous tree species in natural forests of the Poyang Lake Basin. Field investigations on plant communities were conducted in 21 plots from Oct. 2014 to Oct. 2015. These plots were distributed in the Nanling Mountains, Luoxiao Mountains, Wuyi Mountains, Huangshan Mountains, and Jiuling Mountain. The dimensions of each plot were $20 \mathrm{~m} \times 20 \mathrm{~m}$. Community species composition and quantitative characteristics in each plot were recorded. The importance values of trees, shrubs and herbs were computed, respectively. The community types and structural properties were analyzed. A total of 23 sets of community sampling data were obtained in details. A number of 11 species of rare conifers were found in 14 different formations. Rare conifer trees mainly occurred in the communities as co-edificatos or companion species. The formations included Form. Taxus wallichiana var. mairei, Form. Pseudotsuga sinensis, Form. Fokienia hodginsii and Form. Torreya grandis, where the dominant species was coniferous trees. In conclusion, our study provides valuable field investigation data of rare coniferous in Poyang Lake basin, which could provide insight into the protection and management of these species.
\end{abstract}

Key words Poyang Lake basin; rare coniferous; community structure; plots data

Citation: Fang Q, Liu YZ, Ge G (2016). Characteristics of plant communities containing rare conifers in Poyang Lake Basin, China. Chinese Journal of Plant Ecology, 40, 952-957. doi: 10.17521/cjpe.2015.0454

植被生态学是生态学领域最为重要的一部分。 样方数据是研究植被生态学的基础。样方数据的积 累有助于研究大尺度上的生态学问题, 为区域生态 规划提供数据支撑(杨瑶等, 2014)。群落生态学文献 通常少见基础样方数据, 严重限制了研究成果的应
用(张维康等, 2013)。鄱阳湖流域位于中亚热带腹地, 是全球同纬度物种丰富度最高的地区, 在森林植被 中零星保存了一些珍稀针叶树种, 这些珍稀针叶树 种有的以优势种建群, 有的与其他阔叶树共建成为 针阔混交林, 也有的以偶见种出现在群落中(江西

收稿日期Received: 2015-12-10 接受日期Accepted: 2016-05-09

* 通信作者Author for correspondence (E-mail: gge@ncu.edu.cn) 
森林编辑委员会, 1986)。对这些含珍稀针叶树种的 群落进行研究, 有助于理解其保存机制, 也有助于 全面认识江西乃至华东地区森林植被特征, 也可为 鄱阳湖流域的植被研究和森林生态系统管理提供基 础数据。

\section{1 材料和方法}

\section{1 研究区概况}

鄱阳湖流域位于长江中下游南岸, 流域面积 $162225 \mathrm{~km}^{2}$, 属中亚热带季风气候, 年降水量 1656 $\mathrm{mm}$, 年平均气温 $16.7-18.3{ }^{\circ} \mathrm{C}$ 。土壤类型以红壤为 主, 山地分布有少量黄壤及黄棕壤。流域内地形复 杂, 东、南、西三面环山。森林覆盖率 $63.1 \%$ 。本研 究于2014年10月至2015年10月间，对鄱阳湖流域内 含珍稀针叶树种的部分群落进行了调查, 样地分布 于龙南、遂川、井冈山、芦溪、靖安、星子、黎川、 玉山等地, 范围涉及流域内的南岭山地、罗宵山脉、 九岭山脉、武夷山脉、黄山山脉。

\section{2 样地调查}

选择生长良好的天然群落, 设置乔木样方 $20 \mathrm{~m}$ $\times 20 \mathrm{~m}$, 对样方内胸径大于 $2.5 \mathrm{~cm}$ 的立木进行每木 检测, 记录物种名称、高度、冠幅、胸径和枝下高。 在乔木样方内设置 5 个 $(5 \mathrm{~m} \times 5 \mathrm{~m})$ 灌木样方和 5 个 $(1$ $\mathrm{m} \times 1 \mathrm{~m})$ 草本样方, 并记录物种名称、高度、盖度以 及株(丛)数。并记录样地的地理坐标、海拔、坡度、 坡向、坡位、土壤含水量以及土壤腐殖层厚度等环 境因子。 23 个样地基本信息见表 1 , 详细样方数据见 附录。

\section{3 数据分析}

乔木层丰富度为样地内记录的乔木层物种数, 灌木层丰富度为每个样地 5 个灌木样方内记录的总 物种数, 草本层丰富度为每个样地 5 个草本样方内 记录的总物种数。

样地中各层物种重要值按下列公式计算:

乔木层重要值 $=($ 相对高度 + 相对多度 + 相对胸 高断面积) $/ 3 \times 100 \%$

表1 研究区样地基本信息

Table 1 Basic information of plots sampled in the study area

\begin{tabular}{|c|c|c|c|c|c|c|c|c|}
\hline 样地 Plots & 纬度 & Latitude $(\mathrm{N})$ & 经度 & Longitude (E) & 海拔 Altitude (m) & 坡度 Slope gradient & 坡向 Slope aspect & 坡位 Slope position \\
\hline JLS-1 & & $24.53^{\circ}$ & & $114.45^{\circ}$ & 947 & $26^{\circ}$ & 南坡 South & 中坡 Mid-slope \\
\hline JGS-2 & & $26.50^{\circ}$ & & $114.16^{\circ}$ & 1327 & $31^{\circ}$ & 东南坡 Southeast & 上坡 Upper slope \\
\hline JGS-3 & & $26.50^{\circ}$ & & $114.16^{\circ}$ & 1372 & $35^{\circ}$ & 南坡 South & 下坡 Lower slope \\
\hline JGS-5 & & $26.57^{\circ}$ & & $114.12^{\circ}$ & 947 & $10^{\circ}$ & 东坡 East & 下坡 Lower slope \\
\hline JGS-6 & & $26.59^{\circ}$ & & $114.13^{\circ}$ & 979 & $40^{\circ}$ & 南坡 South & 下坡 Lower slope \\
\hline JGS-7 & & $26.58^{\circ}$ & & $114.14^{\circ}$ & 1067 & $30^{\circ}$ & 西北坡 Northwest & 下坡 Lower slope \\
\hline JGS-8 & & $26.57^{\circ}$ & & $114.23^{\circ}$ & 472 & $44^{\circ}$ & 西坡 West & 中坡 Mid-slope \\
\hline JGS-9 & & $26.57^{\circ}$ & & $114.23^{\circ}$ & 516 & $65^{\circ}$ & 西坡 West & 中坡 Mid-slope \\
\hline WGS-1 & & $27.46^{\circ}$ & & $114.13^{\circ}$ & 678 & $6^{\circ}$ & 南坡 South & 下坡 Lower slope \\
\hline WGS-2 & & $27.46^{\circ}$ & & $114.13^{\circ}$ & 672 & $6^{\circ}$ & 北坡 North & 下坡 Lower slope \\
\hline WGS-3 & & $27.46^{\circ}$ & & $114.13^{\circ}$ & 628 & $30^{\circ}$ & 西北坡 Northwest & 下坡 Lower slope \\
\hline PLC-1 & & $29.05^{\circ}$ & & $115.36^{\circ}$ & 111 & $40^{\circ}$ & 西南坡 Southwest & 下坡 Lower slope \\
\hline YQ-1 & & $27.04^{\circ}$ & & $116.92^{\circ}$ & 566 & $12^{\circ}$ & 东坡 East & 下坡 Lower slope \\
\hline YQ-2 & & $27.04^{\circ}$ & & $116.92^{\circ}$ & 598 & $10^{\circ}$ & 东坡 East & 下坡 Lower slope \\
\hline YQ-3 & & $27.04^{\circ}$ & & $116.92^{\circ}$ & 560 & $50^{\circ}$ & 东坡 East & 下坡 Lower slope \\
\hline QX-1 & & $28.43^{\circ}$ & & $114.73^{\circ}$ & 122 & $41^{\circ}$ & 西坡 West & 下坡 Lower slope \\
\hline QX-2 & & $28.46^{\circ}$ & & $114.71^{\circ}$ & 171 & $44^{\circ}$ & 东坡 East & 下坡 Lower slope \\
\hline SQS-1 & & $28.91^{\circ}$ & & $118.06^{\circ}$ & 1620 & $31^{\circ}$ & 东坡 East & 上坡 Upper slope \\
\hline SQS-2 & & $28.91^{\circ}$ & & $118.05^{\circ}$ & 1588 & $28^{\circ}$ & 西南坡 Southwest & 上坡 Upper slope \\
\hline SQS-3 & & $28.92^{\circ}$ & & $118.06^{\circ}$ & 1604 & $20^{\circ}$ & 东南坡 Southeast & 上坡 Upper slope \\
\hline SQS-4 & & $28.92^{\circ}$ & & $118.05^{\circ}$ & 1545 & $28^{\circ}$ & 西坡 West & 上坡 Upper slope \\
\hline SQS-5 & & $28.93^{\circ}$ & & $118.05^{\circ}$ & 1263 & $40^{\circ}$ & 西坡 West & 上坡 Upper slope \\
\hline SQS-6 & & $28.93^{\circ}$ & & $118.05^{\circ}$ & 1267 & $30^{\circ}$ & 西坡 West & 上坡 Upper slope \\
\hline
\end{tabular}


灌木层重要值 $=($ 相对高度 + 相对盖度 + 相对多 度+相对频度) $/ 4 \times 100 \%$

草木层重要值 $=($ 相对高度 + 相对盖度 + 相对多 度+相对频度) $/ 4 \times 100 \%$

\section{2 结果分析}

\section{1 南方红豆杉群系(Form. Taxus wallichiana var.} mairei)

此群系样方位于江西井冈山。土壤为黄壤, 土 层㾑薄, 较多岩石裸露, 土壤平均含水量为 $21.5 \%$, 枯枝落叶层厚度约为 $10 \mathrm{~cm}$, 死地被物覆盖率为 $40 \%$ 。群落位于村庄附近, 有人为干扰现象。样方 数据(附录: 表4)显示, 林冠郁闭度为 $80 \%$, 南方红 豆杉高度3.0-14.5 m, 胸径7.3-80.9 cm, 平均枝下高 $3.1 \mathrm{~m}$ 。乔木层主要伴生种有柳杉(Cryptomeria japonica var. sinensis)、三尖杉(Cephalotaxus fortunei)、 缺薷枫香 (Liquidambar acalycina)、黄山木兰 (Magnolia cylindrica)、青榨槭(Acer davidii)等。灌木 层盖度为 $20 \%$, 高度范围为 $10-165 \mathrm{~cm}$, 物种丰富度 为20, 主要物种为凹叶厚朴(Magnolia officinalis)、

茶(Camellia sinensis)、油茶(Camellia oleifera)、青榨 槭、棕竹(Rhapis excelsa)、缺葶枫香幼苗、秤星树(Ilex asprella)等。草本层盖度为 $50 \%$, 高度 $5-35 \mathrm{~cm}$, 物种 丰富度为 22 , 主要物种为短毛金线草 (Antenoron filiforme var. neofiliforme)、龙芽草(Agrimonia pi$l o s a$ )、麦冬 (Ophiopogon japonicus)、八角麻 (Boehmeria tricuspis)、牛膝(Achyranthes bidentata) 等。

\section{2 香港四照花群系(Form. Cornus hongkongensis)}

此群系为包含南方红豆杉的香港四照花群系, 样方位于江西九连山。土壤为黄壤, 土层㾑薄, 地表 有岩石裸露, 土壤平均含水量为 $24.5 \%$, 枯枝落叶 层厚度约为 $8 \mathrm{~cm}$, 死地被物覆盖率为 $50 \%$ 。乔木层 优势种为香港四照花和南方红豆杉。样方数据(附 录: 表1)显示, 林冠郁闭度为 $90 \%$, 香港四照花高度 4-27 m, 胸径2.8-168.9 cm; 南方红豆杉高度18-27 $\mathrm{m}$, 胸径80.3-137.3 cm, 平均枝下高 $3.5 \mathrm{~m}$ 。乔木层 主要伴生种有山拐疋(Poliothyrsis sinensis)、钩雉 (Castanopsis tibetana)、厚斗柯(Lithocarpus elizabethiae)等。灌木层盖度为 $85 \%$, 高度 5-200 cm, 物种 丰富度为 52 , 主要物种为山香圆 (Turpinia montana)、厚斗柯、大叶新木姜子(Neolitsea levinei)、野
含笑(Michelia skinneriana)、枳(Citrus trifoliata)、岭 南山茉莉(Huodendron biaristatum var. parviflorum) 等。草本层盖度为 $60 \%$, 高度 $10-60 \mathrm{~cm}$, 物种丰富度 为 14 , 主要物种为楼梯草(Elatostema involucratum)、 点囊喜草 (Carex rubrobrunnea)、蓱 (Pteridium aquilinum var. latiusculum)、花叶山姜 (Alpinia pumila)、短毛金线草等。

\section{3 鞋毛竹群系(Form. Phyllostachys edulis)}

此群系为包含南方红豆杉和篦子三尖杉 (Cephalotaxus oliveri)的毛竹群系, 样方位于江西井 冈山和武功山。土壤为山地黄壤, 土层较厚, 土壤含 水量约为 $32.1 \%$, 枯枝落叶层厚度3-8 cm, 死地被 物覆盖度为 $30 \%-40 \%$ 。群落内优势层主要物种为毛 竹, 伴生种为南方红豆杉、篦子三尖杉、缺苟枫香 等。尤其以毛竹和南方红豆杉混交群系较为常见。 样方数据显示(附录: 表 5 , 表 11 ), 林冠郁闭度为 80\%-90\%，毛竹高度 $2.5-16.0 \mathrm{~m}$, 胸径 $2.9-13.4 \mathrm{~cm}$; 南方红豆杉高度8-16 m, 胸径31.2-53.2 cm; 篦子 三尖杉高度1.7-3.5 m, 胸径1.9-4.1 cm。灌木层盖度 $40 \%-70 \%$, 高度 20-250 cm, 物种丰富度为 $22-23$, 主要物种为篦子三尖杉、茶、油茶、聯木 (Loropetalum chinense)、绿叶甘橿等。草本层盖度为 $50 \%$, 高度 5-100 cm, 物种丰富度为 10-16, 主要物种为短毛金 线草、虎杖(Reynoutria japonica)、求米草(Oplismenus undulatifolius)、假楼梯草(Lecanthus peduncularis)、 乌蕨(Stenoloma chusana)等。

\section{4 杉木群系(Form. Cunninghamia lanceolata)}

此群系为包含篦子三尖杉的杉木群系, 样方位 于江西武功山。土壤为山地黄壤, 土层较厚, 土壤含 水量约为 $37.5 \%$, 枯枝落叶层厚度约为 $10 \mathrm{~cm}$, 死地 被物覆盖度为 $50 \%$ 。群落内高大乔木主要为杉木, 小乔木及灌木主要为篦子三尖杉, 群落位于村庄附 近, 沟谷溪流旁。样方数据(附录: 表10)显示, 林冠 郁闭度为 $85 \%$, 杉木高度 5-12 m, 胸径7.2-33.8 cm, 篦子三尖杉高度 $1.8-4.0 \mathrm{~m}$, 胸径 $2.5-6.2 \mathrm{~cm}$, 平均枝 下高 $0.8 \mathrm{~m}$ 。灌木层盖度为 $80 \%$, 高度 $15-210 \mathrm{~cm}$, 物 种丰富度为 24 , 主要物种为篦子三尖杉、绿叶甘橿 (Lindera neesiana)、篌竹(Phyllostachys nidularia)、 油茶、野蓄薇(Rosa multiflora)、白檀(Symplocos paniculata) 等。草本层盖度为 $75 \%$, 高度 5-60 cm, 物 种丰富度为 18 , 主要物种为辣蓼 (Polygonum hydropiper)、短毛金线草、假楼梯草、阔叶凤尾蒝、求米 
草、石荠䓬(Mosla scabra)等。

\section{5 楝群系(Form. Melia azedarach)}

此群系为包含篦子三尖杉的楝群系, 样方位于 江西武功山。土壤为山地黄壤, 土层较厚, 地表裸露 岩石较少, 土壤含水量约为 $40.7 \%$, 枯枝落叶层厚 度约为 $15 \mathrm{~cm}$, 死地被物覆盖度为 $70 \%$ 。群落内高大 乔木主要为苦楝和油桐 (Vernicia fordii), 小乔木及 灌木主要为篦子三尖杉、檵木等, 群落位于村庄附 近, 沟谷溪流旁。样方数据(附录: 表9)显示, 林冠郁 闭度为 $85 \%$, 苦楝高度 $10 \mathrm{~m}$, 胸径 $25.8 \mathrm{~cm}$, 篦子三 尖杉高度1.7-3.5 m, 胸径2.4-4.5 cm。灌木层盖度为 $90 \%$, 高度 40-200 cm, 物种丰富度为 17 , 主要物种 为㶌木、算盘子(Glochidion puberum)、篦子三尖杉、 六月雪(Serissa japonica)、白檀、茶、油茶等。草本 层盖度为 $60 \%$, 高度范围为 $8-100 \mathrm{~cm}$, 物种丰富度 为 20 , 主要物种为辣苶、紫苑(Aster tataricus)、短毛 金线草、龙葵(Solanum nigrum)、楼梯草、求米草、 石荠苦等。

\section{6 福建柏群系(Form. Fokienia hodginsii)}

此群系样方位于江西井冈山。土壤为山地黄棕 壤, 土层较厚, 地表裸露岩石较少, 土壤含水量约 为 $31 \%$, 枯枝落叶层厚度为 $10-20 \mathrm{~cm}$, 死地被物覆 盖度为 $100 \%$ 。群落位于景区内, 有人为干扰现象。 样方数据(附录: 表 2 , 表 3) 显示, 林冠郁闭度为 85\%-90\%, 福建柏(Fokienia hodginsii)高度6-16 m, 胸径8-45 cm, 平均枝下高 $6.7 \mathrm{~m}$, 乔木层丰富度为 25-28, 主要伴生种为甜槠 (Castanopsis eyrei)、马银 花(Rhododendron ovatum)、黄山松(Pinus taiwanensis)、日本杜英(Elaeocarpus japonicus)、格药柃 (Eurya muricata)、光亮山矾(Symplocos lucida) 等。 灌木层盖度为 $80 \%$, 高度 $5-350 \mathrm{~cm}$, 物种丰富度为 13-32, 主要物种为光叶铁仔 (Myrsine stolonifera)、 美丽新木姜子(Neolitsea pulchella)、格药柃、银木荷 (Schima argentea)、朱砂根(Ardisia crenata)、厚叶厚 皮香(Ternstroemia kwangtungensis)等。草本层盖度 为 $15 \%-20 \%$, 高度 $10-55 \mathrm{~cm}$, 物种丰富度为 $4-6$, 主 要物种为三穗薹草 (Carex tristachya)、斑叶兰 (Goodyera schlechtendaliana)、瘤足葓(Plagiogyria adnata)、狗脊(Woodwardia japonica) 等。

\section{7 榧树群系(Form. Torreya grandis)}

此群系样方位于江西岩泉自然保护区。土壤为 山地黄壤, 土层较厚, 地表裸露岩石较少, 土壤含
水量约为 $29 \%$, 枯枝落叶层厚度为 $10-20 \mathrm{~cm}$, 死地 被物覆盖度为 $75 \%-90 \%$ 。群落周围多为毛竹 (Phyllostachys edulis)林或竹阔混交林。样方数据(附 录: 表13-15)显示，林冠郁闭度为 $70 \%-80 \%$ ，榧树 高度3-17 m, 胸径3.5-115.0 cm, 平均枝下高 $2.1 \mathrm{~m}$, 乔木层丰富度为6-12。灌木层盖度为 $15 \%-30 \%$ ，高 度范围为 $15-180 \mathrm{~cm}$, 物种丰富度为 $10-23$, 主要物 种为茶、小蜡(Ligustrum sinense)、八角枫(Alangium chinense)、红背山麻杆(Alchornea trewioides)、细枝 柃 (Eurya loquaiana)、六月雪等。草本层盖度为 $30 \%-50 \%$, 高度 $5-40 \mathrm{~cm}$, 物种丰富度为 $11-13$, 主 要物种为蝴蝶花 (Iris japonica)、阔鳞鳞毛萨、求米 草、楼梯草、假楼梯草等。

\section{8 竹柏群系(Form. Nageia nagi)}

此群系样方位于江西官山。土壤为山地黄壤, 土层较薄, 地表裸露岩石多, 枯枝落叶层厚度约为 5 $\mathrm{cm}$, 死地被物覆盖度为 $80 \%-85 \%$, 群落位于沟谷溪 流旁。样方数据(附录: 表16, 表17)显示, 林冠郁闭 度为 $75 \%-80 \%$, 竹柏高度 $2.5-11.0 \mathrm{~m}$, 胸径 $2.5-24.2$ $\mathrm{cm}$, 平均枝下高 $1.1 \mathrm{~m}$ 。乔木层主要伴生种为赤杨叶 (Alniphyllum fortunei)、化香树 (Platycarya strobilacea)、鼠刺(Itea chinensis)、野桐(Mallotus tenuifolius)、木荷 (Schima superba) 等。灌木层盖度为 $60 \%-70 \%$, 高度30-300 cm, 物种丰富度为4-8, 主 要物种为苦竹(Pleioblastus amarus)、杜茎山(Maesa japonica)、阔叶箬竹(Indocalamus latifolius)、短柄紫 珠(Callicarpa brevipes)、竹柏幼苗等。草本层盖度 为 $30 \%-50 \%$, 高度 $10-60 \mathrm{~cm}$, 物种丰富度为 $4-9$, 主 要物种为求米草、阔鳞鳞毛蕨、楼梯草、狗脊、阔 叶凤尾葓(Pteris esquirolii)等。

\section{9 青冈群系(Form. Cyclobalanopsis glauca)}

本群系为包含竹柏的青冈群系, 样方位于江西 九岭山。土壤为黄壤, 土层较薄, 地表裸露石块较 多, 地形陡峭, 土壤含水量约为 $20 \%$, 枯枝落叶层 厚度约为 $10 \mathrm{~cm}$, 死地被物覆盖度为 $70 \%$ 。群落位于 村庄附近, 具有人为干扰现象。群落乔木层主要物 种为青冈、苦槠栲(Castanopsis sclerophylla)、山乌 柏(Triadica cochinchinensis)、竹柏、栲(Castanopsis fargesii)等。据当地护林员介绍, 本样地及附近原为 竹柏群落, 由于人为偷盗严重, 逐渐成为以青冈为 优势种的群落。样方数据(附录: 表12)显示, 林冠郁 闭度为 $90 \%$, 青冈高度 $2.5-10.0 \mathrm{~m}$, 胸径 3.2-43.6 
$\mathrm{cm}$; 竹柏高度2.0-8.5 m, 胸径2.5-7.6 cm。灌木层盖 度为 $50 \%$, 高度 $30-130 \mathrm{~cm}$, 物种丰富度为 16 , 主要 物种为青冈幼苗、竹柏幼苗、赤楠(Syzygium buxifolium)、鼠刺、羊舌树(Symplocos glauca)、马醉木 (Pieris japonica) 等。草本层盖度为 $30 \%$, 高度范围为 20-30 cm, 物种丰富度为 3 , 主要物种为圆盖阴石蒝 (Humata tyermannii)、阔鳞鳞毛葓、三穗薹草等。

\subsection{0 赤杨叶群系(Form. Alniphyllum fortunei)}

此群系为包含穗花杉(Amentotaxus argotaenia) 的赤杨叶群系, 样方位于江西井冈山。土壤为黄壤, 土层较厚, 地表裸露岩石较少, 土壤含水量约为 $34.5 \%$, 枯枝落叶层厚度约为 $15 \mathrm{~cm}$, 死地被物覆盖 度为 $45 \%$ 。群落位于沟谷溪流边, 周围为常绿阔叶 林, 林下植被茂密。乔木层主要物种为赤杨叶、深 山含笑(Michelia maudiae)、穗花杉、大叶新木姜子 等。样方数据(附录: 表8)显示, 林冠郁闭度为 $80 \%$, 赤杨叶高度 $17.5 \mathrm{~m}$, 胸径 $46.8 \mathrm{~cm}$; 穗花杉高度 2.5-11.0 m, 胸径2.9-22.3 cm。灌木层盖度为70\%, 高度30-175 cm, 物种丰富度为 21 , 主要物种为细枝 柃、柏拉木(Blastus cochinchinensis)、穗花杉幼树、 阔叶箬竹、深山含笑等。草本层盖度为 $50 \%$, 高 度7.0-52.5 cm, 物种丰富度为 15 , 主要物种为楼梯 草、山姜(Alpinia japonica)、三穗薹草、花葶臺草 (Carex scaposa)、假楼梯草、藜芦(Veratrum nigrum) 等。

\subsection{1 钩锥群系(Form. Castanopsis tibetana)}

此群系为包含穗花杉的钩锥群系, 样方位于江 西井冈山。土壤为黄棕壤, 土层较厚, 地表裸露岩石 少, 土壤含水量约为 $24.5 \%$, 枯枝落叶层厚度约为 $15 \mathrm{~cm}$, 死地被物覆盖度为 $75 \%$ 。群落位于沟谷溪流 边, 周围为常绿润叶林, 林下植被茂密。乔木层主要 物种为钩雉、穗花杉、皇荚(Gleditsia sinensis)、深 山含笑等。样方数据(附录: 表7)显示, 林冠郁闭度 为 $95 \%$, 钩锥高度 9.0-14.5 m, 胸径 20.1-47.8 cm; 穗花杉高度1.7-13.0 m, 胸径1.6-14.3 cm。灌木层盖 度为 $60 \%$, 高度30-220 cm, 物种丰富度为 29 , 主要 物种为细枝柃、茶、红楠、栓叶安息香 (Styrax suberifolius)、薄叶润楠(Machilus leptophylla)、柏拉 木、青冈, 以及少量穗花杉幼苗等。草本层盖度为 $60 \%$, 高度15.0-36.7 cm, 物种丰富度为 19 , 主要物 种为楼梯草、山姜、瘤足蕨、小三叶耳硕(Polystichum hancokii)、贯众(Cyrtomium fortunei)、牛膝等。

\subsection{2 黄山松群系(Form. Pinus taiwanensis)}

此群系样方位于江西井冈山和三清山。土壤为 山地黄壤, 土壤贫癐, 地表裸露岩石较多, 土壤含 水量约为 $40 \%$, 枯枝落叶层厚度为 $5-15 \mathrm{~cm}$, 死地被 物覆盖度为 $80 \%$ 。群落位于山脊, 无人为干扰。样 方数据 (附录: 表 6 , 表 19-21)显示, 林冠郁闭度为 90\%, 黄山松高度4-15 m, 胸径7.6-46.5 cm, 平均 枝下高 $5.4 \mathrm{~m}$, 乔木层丰富度为5-17。灌木层盖度为 $65 \%-95 \%$, 高度 $5-250 \mathrm{~cm}$, 物种丰富度为 $8-22$, 主 要物种为绿叶甘槚 (Lindera neesiana) 、交让木 (Daphniphyllum macropodum)、杜鹃(Rhododendron simsii)、玉山竹(Yushania niitakayamensis)、醉鱼草 (Buddleja lindleyana)、浙江山茶(Camellia chekiangoleosa)、岩柃 (Eurya saxicola)、格药柃等。草本层 盖度为 $20 \%-50 \%$, 高度 $5-40 \mathrm{~cm}$, 物种丰富度为 $2-9$, 主要物种为狗脊䓲、求米草、沿阶草(Ophiopogon bodinieri)、三穗薹草、阔鳞鳞毛蕨 (Dryopteris championii)等。

\subsection{3 黄杉群系(Form. Pseudotsuga sinensis)}

此群系样方位于三清山。土壤为棕壤, 土层较 薄, 地表裸露岩石较大、较多, 枯枝落叶层厚度约为 $5 \mathrm{~cm}$, 死地被物覆盖度为 $90 \%$ 。群落内分层明显, 乔 木层主要为黄杉、猴头杜鹃 (Rhododendron simiarum)、多脉青冈(Cyclobalanopsis multinervis)、青冈 (Cyclobalanopsis glauca)、黄山松等, 灌木层主要为 扁枝越橘(Vaccinium japonicum var. sinicum) 等。样方 数据(附录: 表23)显示, 林冠郁闭度为 $75 \%$, 黄杉高 度范围10-18 m, 胸径范围17.8-75.5 cm, 平均枝下 高 $6.2 \mathrm{~m}$ 。灌木层盖度为 $80 \%$, 高度范围为 $10-220$ $\mathrm{cm}$, 物种丰富度为 30 , 主要物种为猴头杜鹃、扁枝 越橘、山矾(Symplocos sumuntia)、浙汇山茶、朱砂 根、毛漆树(Toxicodendron trichocarpum), 以及少量 黄杉幼苗等。草本层盖度为 $40 \%$, 高度5-30 cm, 物 种丰富度为 9 , 主要物种为三穗薹草、麦冬、春兰 (Cymbidium goeringii)、玉山针萄 (Trichophorum subcapitatum)、沿阶草等。

\subsection{4 猴头杜鹃群系(Form. Rhododendron simia- rum)}

此群系为含黄杉的猴头杜鹃群系，样方位于江 西三清山。土壤为棕壤, 土层较薄, 地表裸露岩石较 大、较多, 枯枝落叶层厚度为 $5-10 \mathrm{~cm}$, 死地被物覆 盖度为 $80 \%$ 。群落内分层明显, 乔木层主要为猴头 
杜鹃(Rhododendron simiarum)、黄杉、雷公鹅耳枥 (Carpinus viminea)、黄山松、岩柃、多脉青冈等, 灌 木层主要为玉山竹、猴头杜鹃等。样方数据(附录: 表 18 , 表22)显示, 林冠郁闭度为 $85 \%-90 \%$, 乔木层 主要为黄杉和猴头杜鹃, 黄杉高度 3-23 m, 胸径 7.0-101.9 cm, 平均枝下高 $5.4 \mathrm{~m}$; 猴头杜鹃高度 2-10 m, 胸径3.2-23.9 cm。灌木层盖度为60-90\%, 高度 5-200 cm, 物种丰富度为14-25, 主要物种为猴 头杜鹃、玉山竹、朱砂根、岩柃, 以及少量黄杉幼 苗等。草本层盖度为 $15 \%-20 \%$, 高度 5-60 cm, 物种 丰富度为6-9, 主要物种为三穗薹草、麦冬(Ophiopogon japonicus)、多花黄精(Polygonatum cyrtonema)、 斑叶兰、野菊(Chrysanthemum indicum)、宽叶茥草 (Carex siderosticta)、金星蕨(Parathelypteris glanduligera)等。

基金项目 国家科技基础性工作专项(2015FY110200)和国家自然科学基金(31260110)。

\section{参考文献}

The Editorial Committee of Forest of Jiangxi (1986). Forest of Jiangxi. Jiangxi Science and Technology Press, Nanchang. (in Chinese) [江西森林编辑委员会 (1986). 江西森林. 江西科学技术出版社, 南昌.]

Yang Y, Guo K, Zhao LQ, Zhao HW, Qiao XG, Liu HM (2014). Community characteristics of Stipa roborowskyi steppe in Xizang. Chinese Journal of Plant Ecology, 38, 635-639. (in Chinese with English abstract) [杨瑶, 郭柯, 赵利清, 赵海卫, 乔鲜果, 刘慧明 (2014). 西藏昆仑针 茅草原的基本特征. 植物生态学报, 38, 635-639.]

Zhang WK, Li H, Wang GH (2013). Community characteristics of main vegetation types along two altitudinal transects on mountains of northwestern Beijing, China. Chinese Journal of Plant Ecology, 37, 566-570. (in Chinese with English abstract) [张维康, 李贺, 王国宏 (2013). 北京西北 部山地两个垂直样带内主要植被类型的群落特征. 植物 生态学报, 37, 566-570.]

附录I 鄱阳湖流域含珍稀针叶树种的群落样方数据

Appendix I Plots data of plant communities containing rare conifers in Poyang Lake Basin http://www.plant-ecology.com/fileup/PDF/cjpe.2015.0454-D1.xls

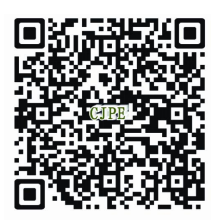

植物生态学报官网

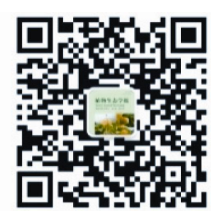

微信订阅号 期刊及学科 相关信息发布

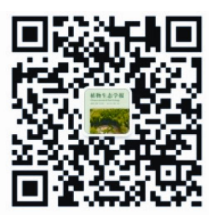

微信服务号

稿件状态查询 全文检索汶览 